\title{
Role of Caveolae in Cardiac Protection
}

\author{
David M. Roth $\cdot$ Hemal H. Patel
}

Received: 17 December 2010/ Accepted: 20 December 2010/Published online: 6 January 2011

(C) The Author(s) 2011. This article is published with open access at Springerlink.com

\begin{abstract}
Myocardial ischemia/reperfusion injury is a major cause of morbidity and mortality. The molecular signaling pathways involved in cardiac protection from myocardial ischemia/reperfusion injury are complex. An emerging idea in signal transduction suggests the existence of spatially organized complexes of signaling molecules in lipid-rich microdomains of the plasma membrane known as caveolae. Caveolins-proteins abundant in caveolaeprovide a scaffold to organize, traffic, and regulate signaling molecules. Numerous signaling molecules involved in cardiac protection are known to exist within caveolae or interact directly with caveolins. Over the last 4 years, our laboratories have explored the hypothesis that caveolae are vitally important to cardiac protection from myocardial ischemia/reperfusion injury. We have provided evidence that (1) caveolae and the caveolin isoforms 1 and 3 are essential for cardiac protection from myocardial ischemia/ reperfusion injury, (2) stimuli that produce preconditioning of cardiac myocytes, including brief periods of ischemia/ reperfusion and exposure to volatile anesthetics, alter the number of membrane caveolae, and (3) cardiac myocytespecific overexpression of caveolin-3 can produce innate cardiac protection from myocardial ischemia/reperfusion injury. The work demonstrates that caveolae and caveolins are critical elements of signaling pathways involved in
\end{abstract}

\section{M. Roth $(\varangle) \cdot$ H. H. Patel}

VA Medical Center (125), Veterans Affairs San Diego Healthcare System, 3350 La Jolla Village Drive, San Diego, CA 92161-5085, USA

e-mail: droth@ucsd.edu

D. M. Roth · H. H. Patel

Department of Anesthesiology, University of California,

San Diego, CA, USA

e-mail: hepatel@ucsd.edu cardiac protection and suggests that caveolins are unique targets for therapy in patients at risk of myocardial ischemia.

Keywords Caveolae - Ischemia/reperfusion injury · Cardiac protection

\section{Introduction: A Role for Caveolae in Cardiac Protection from Myocardial Ischemia/Reperfusion Injury}

Myocardial ischemia/reperfusion injury and resultant myocardial infarction remains a major cause of death. One of the most beneficial experimental interventions to produce cardiac protection from myocardial ischemia/reperfusion injury is termed ischemic preconditioning (IPC) [22]. IPC occurs when the myocardium is exposed to brief (as short as $5 \mathrm{~min}$ ) ischemia resulting in protection from subsequent prolonged (up to $60 \mathrm{~min}$ ) ischemia. IPC is a biphasic event: The acute phase occurs immediately after the IPC stimulus and lasts $1-3 \mathrm{~h}$ and is transient [19]. The delayed phase of protection is seen 12-24 h after the initial stimulus and lasts up to $72 \mathrm{~h}$ [21]. Cardiac protection in which the cardiac protective strategy is applied at the time of reperfusion has been termed postconditioning [40]. IPC and postconditioning are promiscuous stimuli that involve the initiation of many shared and interconnected signaling pathways [10-12, 15] (Fig. 1). There is uncertainty as to how signaling molecules interact within cells to produce cardiac protection. We propose that the signal components in cardiac protection coexist and function in a lipid-rich environment (caveolae) and that the interaction of signaling molecules with caveolins is necessary for cardiac protection. 


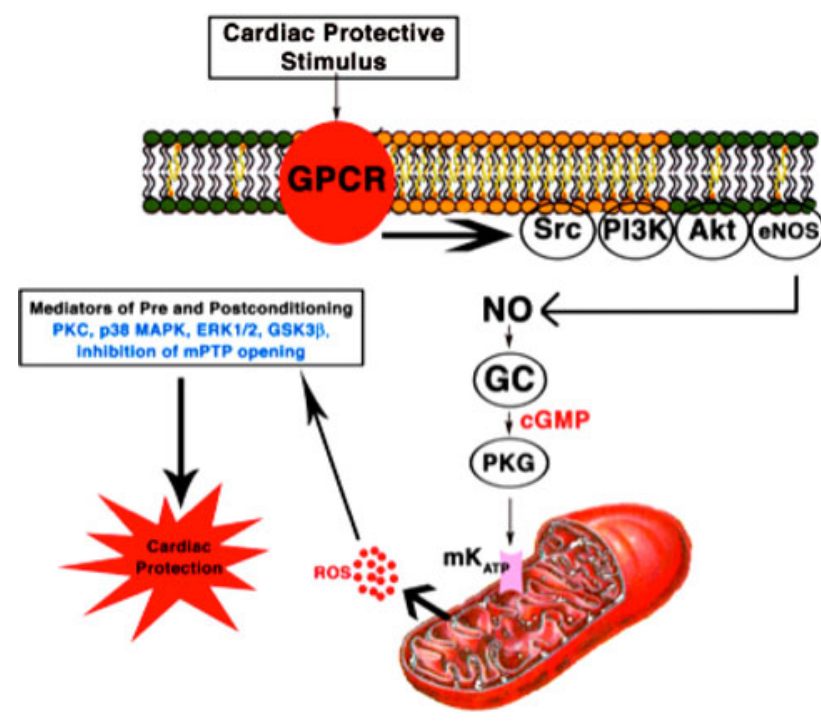

Fig. 1 Overview of the signaling molecules involved in cardiac protection. ROS reactive oxygen species, $N O$ nitric oxide, $G C$ guanylyl cyclase (Adapted from [10])

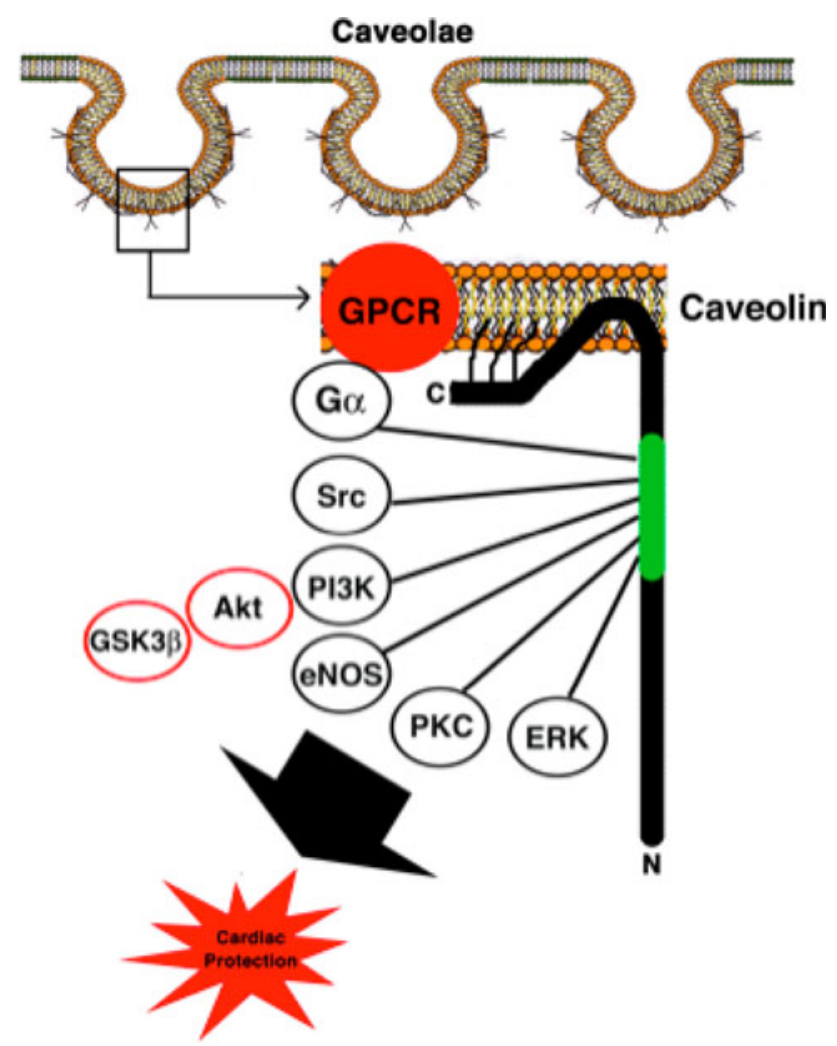

Fig. 2 Signaling molecules involved in cardiac protection known to localize in caveolae and interact with the scaffolding domain (green) of caveolin

Caveolae, or "little caves" (Fig. 2) are cholesteroland sphingolipid-enriched invaginations of the plasma membrane [23] and are a subset of lipid rafts [29]. Caveolins-the structural proteins essential for caveolae formation-are present in three isoforms [2, 24]. Caveolin1 and caveolin-2 (Cav-1 and Cav-2) are expressed in multiple cell types, whereas caveolin-3 (Cav-3) is found primarily in striated (skeletal and cardiac) muscle and certain smooth muscle cells [33]. Caveolins are involved in multiple cellular processes, including vesicular transport, cholesterol and calcium homeostasis [8, 9, 14, 28, 31], and signal transduction [3, 20, 34, 37]. Caveolins function as chaperones and scaffolds via a scaffolding domain recruiting signaling molecules to caveolae to provide direct temporal and spatial regulation of signal transduction [32, 37]. Caveolins can inhibit proteins by interaction with a caveolin-binding motif present in proteins, including eNOS and ERK1/2 [5, 7, 16]. Alternatively, caveolins can promote signaling via enhanced receptor-effector coupling or enhanced receptor affinity when caveolins are upregulated or overexpressed [6, 30, 38].

Preconditioning and postconditioning are mediated via a complex molecular signaling cascade known as the reperfusion injury salvage kinase (RISK) pathway [12]. In addition to sublethal ischemia and reperfusion, several pharmaceuticals including opioids and volatile anesthetics produce preconditioning and postconditioning via similar signaling cascades [27]. Many RISK pathway molecules associate with caveolae and caveolins, including G-protein coupled receptors (GPCRs), receptor tyrosine kinases (RTKs), Src kinases, G-proteins, H-Ras, nitric oxide synthases, protein kinase $\mathrm{C}$ (PKC), phosphatidylinositol 3-kinase (PI3K), and MEK/ERK kinases (Fig. 2) [18]. Further evidence that caveolins are involved in cardiac protection stems from the finding that infusion of the caveolin scaffolding domain peptide of Cav-1 into ischemic/ reperfused hearts increased the recovery of cardiac function [39]. Subsequently, it was shown that ischemia/reperfusion injury activated mitogen-activated protein kinases, redistributed Cav-3, and downregulated expression of Cav-1, limiting the negative impact of Cav-1 on eNOS [1]. This suggested a potential mechanism for IPC via increased generation of NO during lethal ischemia [4]. Others showed that IPC can modulate the microenvironment of caveolae to enrich for proteins that promote cardiac protection, including eNOS and the glucose transporter GLUT-4 that translocate to caveolae after IPC [17].

\section{Caveolae and Caveolins are Essential for Cardiac Protection from Ischemia/Reperfusion Injury}

We first set out to test the hypothesis that caveolae and caveolins are critical elements of the signaling pathways involved in cardiac protection from ischemia/reperfusion injury. In a novel set of experiments, we investigated the role of caveolae in IPC and opioid-receptor-mediated 
cardiac protection [25]. In cardiac myocytes isolated from adult rats we determined protein expression and localization of the $\delta$-opioid receptor using coimmunohistochemistry, caveolar fractionation, and immunoprecipitations. The $\delta$-opioid receptor colocalized in fractions with Cav-3 and could be immunoprecipitated by a Cav-3 antibody. Immunohistochemistry confirmed plasma membrane colocalization of the $\delta$-opioid receptor with Cav-3. Cardiac myocytes were subjected to simulated ischemia $(2 \mathrm{~h})$ or an IPC protocol (10 min ischemia, $30 \mathrm{~min}$ recovery, $2 \mathrm{~h}$ ischemia) in the presence and absence of methyl- $\beta$-cyclodextrin, which binds cholesterol and disrupts caveolae. We also assessed the cardiac protective effects of SNC-121-a selective $\delta$-opioid receptor agonist—on cardiac myocytes with or without methyl- $\beta$-cyclodextrin and methyl$\beta$-cyclodextrin preloaded with cholesterol. Ischemia, simulated by mineral oil layering to inhibit gas exchange, promoted cardiac myocyte cell death as assessed by trypan blue staining - a response blunted by SNC-121 or by use of the IPC protocol. Methyl- $\beta$-cyclodextrin treatment, which disrupted caveolae (as detected by electron microscopy), fully attenuated the protective effects of IPC or SNC-121, resulting in cell death comparable to that of the ischemic group. In contrast, protection was not blocked in cells incubated with cholesterol-saturated methyl- $\beta$-cyclodextrin, which maintained caveolae structure and function. These findings were the first to suggest a key role for caveolae, perhaps through enrichment of signaling molecules, in contributing to cardiac protection from ischemia/ reperfusion injury.

We next investigated the role of caveolae and the specific caveolin molecules in cardiac protection. We tested the hypothesis that caveolae and Cav-3 are essential for volatile anesthetic-induced cardiac protection using cardiac myocytes from adult rats and in vivo studies in Cav-3 knockout mice (Cav-3-/-) [13]. Cav-3-/- mice lack Cav-3 and caveolae in their cardiac myocyte membranes. We incubated normal adult rat cardiac myocytes with methyl- $\beta$-cyclodextrin or colchicine to disrupt caveolae formation and then exposed the myocytes to the volatile anesthetic isoflurane for $30 \mathrm{~min}$ at $1.4 \%$, followed by simulated ischemia/reperfusion in a hypoxic chamber. Isoflurane protected cardiac myocytes from simulated ischemia/reperfusion, but this protection was abolished by methyl- $\beta$-cyclodextrin or colchicine. Membrane fractionation by sucrose density gradient centrifugation of myocytes treated with methyl- $\beta$-cyclodextrin or colchicine revealed that buoyant (caveolae-enriched) fractions had decreased phosphoCav- 1 and Cav- 3 compared to control cardiac myocytes. Cardiac protection in vivo was assessed by measurement of infarct size relative to the area at risk and cardiac troponin levels. Isoflurane induced a reduction in infarct size and cardiac troponin relative to control.
Isoflurane-induced cardiac protection was abolished in Cav-3-/- mice. We concluded that caveolae and Cav-3 were critical elements involved in volatile anestheticinduced cardiac protection from ischemia/reperfusion injury.

We also explored a specific role for Cav-1 in cardiac protection using in vitro and in vivo models of ischemia/ reperfusion injury, transgenic mice, and biochemical assays [26]. We found that Cav-1 mRNA and protein were expressed in adult mouse cardiac myocytes. The volatile anesthetic isoflurane protected cardiac myocytes from hypoxia-induced cell death. Hearts of wild-type (WT) mice showed rapid phosphorylation of Src and Cav-1 after isoflurane and ischemic preconditioning. The Src inhibitor PP2 reduced phosphorylation of Src (Y416) and Cav-1 in the heart and abolished isoflurane-induced cardiac protection in wild-type mice. Infarct size was reduced by isoflurane in WT mice but not Cav-1-/- mice. Cav-1-/mice exposed to isoflurane showed significant alterations in Src phosphorylation and recruitment of C-terminal Src kinase-a negative regulator of Src-when compared to WT mice. The results indicated that activation of Src and phosphorylation of Cav-1 are critical steps in the signaling pathways involved in cardiac protection. Our recent study indicates that delayed protection is still present in Cav-1-/- but not Cav-3-/-, suggesting that the caveolae formation (dependent on Cav-3) might be a common element to both acute and delayed cardiac protection [36].

\section{Overexpression of Cav-3 Produces Innate Cardiac Protection from Ischemia/Reperfusion Injury}

A key finding for our laboratories was that stimuli that can invoke cardiac protection from ischemia/reperfusion injury such as sublethal ischemia and volatile anesthetics actually alter sarcolemmal membrane ultrastructure and increase the number of formed caveolae (Fig. 3) [26, 35]. Given these findings, we tested the hypothesis that cardiac myocyte-specific overexpression of Cav-3 would enhance the formation of caveolae and augment innate cardiac protection in vivo. We showed that adenovirus for Cav-3 increased caveolar formation and phosphorylation of survival kinases in cardiac myocytes in vitro. We then produced a transgenic mouse with cardiac myocyte-specific overexpression of Cav- 3 using the $\alpha$-myosin heavy-chain promoter (Cav-3 OE mice) and showed enhanced formation of caveolae on the cardiac myocyte sarcolemmal of these mice. Cav-3 OE mice subjected to ischemia/reperfusion injury had a significantly reduced infarct size relative to transgene-negative control mice. Innate cardiac protection in Cav-3 OE mice was similar to WT mice undergoing IPC and no increased protection was observed 


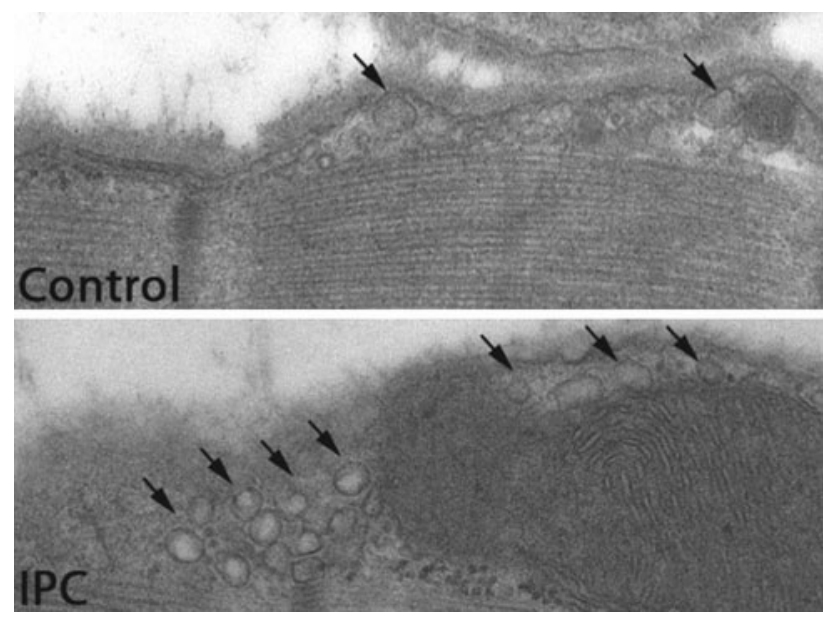

Fig. 3 Mice underwent ischemic preconditioning (IPC, $5 \mathrm{~min}$ of ischemia and then reperfusion) and hearts were perfusion fixed at 15 min of reperfusion with $2.5 \%$ glutaraldehyde in $0.1 \mathrm{M}$ cacodylate buffer for $2 \mathrm{~h}$ at room temperature, postfixed in $1 \% \mathrm{OsO}_{4}$ in $0.1 \mathrm{M}$ cacodylate buffer $(1 \mathrm{~h})$ at room temperature. Control animals underwent sham surgery. Representative electron microscopy images show that IPC increases membrane invaginations that are typical features of caveolae

in preconditioned Cav-3 OE mice. Additionally, Cav-3 knockout mice did not show innate protection and showed no protection in response to preconditioning. Cav-3 OE mouse hearts had increased basal Akt and GSK3 $\beta$ phosphorylation comparable to WT mice exposed to IPC. Wortmannin-a PI3K inhibitor-attenuated basal phosphorylation of Akt and GSK $3 \beta$ and blocked cardiac protection in Cav-3 OE mice. Cav-3 OE mice had improved functional recovery and reduced apoptosis at $24 \mathrm{~h}$ of reperfusion following an initial $30 \mathrm{~min}$ of ischemia. We concluded that expression of Cav-3 is both necessary and sufficient for cardiac protection and that increased expression of caveolins has the potential to protect hearts exposed to ischemia/reperfusion injury.

\section{Conclusions}

Cardiac protective strategies geared toward myocardial ischemia/reperfusion injury are of major interest. It is now clear that the caveolin protein family plays a diverse and critical role in the cardiovascular system and a significant role in cardiac protective signaling. However, our understanding of the underlying mechanisms involved with caveolae, caveolins, and cardiac protection remains limited and an exciting area for active investigation. Further basic science research and eventual randomized clinical trials are needed to define the precise mechanisms and therapeutic potential of caveolins in patients at risk of myocardial ischemia.
Acknowledgments This work was supported by a VA Merit Grant (to Dr. Roth) from the Department of Veterans Affairs, Washington, DC and National Institutes of Health grants HL081400 (to Dr. Roth), HL066941 (to Dr. Roth), and HL091071 (to Dr. Patel) from the United States Public Health Service, Bethesda, MD.

Open Access This article is distributed under the terms of the Creative Commons Attribution Noncommercial License which permits any noncommercial use, distribution, and reproduction in any medium, provided the original author(s) and source are credited.

\section{References}

1. Ballard-Croft C, Locklar AC, Kristo G, Lasley RD (2006) Regional myocardial ischemia induced activation of MAPKs is associated with subcellular redistribution of caveolin and cholesterol. Am J Physiol Heart Circ Physiol 291:H658-H667

2. Chun M, Liyanage UK, Lisanti MP, Lodish HF (1994) Signal transduction of a $\mathrm{G}$ protein-coupled receptor in caveolae: colocalization of endothelin and its receptor with caveolin. Proc Nat Acad Sci USA 91:11728-11732

3. Cohen AW, Hnasko R, Schubert W, Lisanti MP (2004) Role of caveolae and caveolins in health and disease. Physiol Rev 84:1341-1379

4. Der P, Cui J, Das DK (2006) Role of lipid rafts in ceramide and nitric oxide signaling in the ischemic and preconditioned hearts. J Mol Cell Cardiol 40:313-320

5. Engelman JA, Chu C, Lin A, Jo H, Ikezu T, Okamoto T, Kohtz DS, Lisanti MP (1998) Caveolin-mediated regulation of signaling along the p42/44 MAP kinase cascade in vivo. A role for the caveolin-scaffolding domain. FEBS Lett 428:205-211

6. Feron O, Balligand JL (2006) Caveolins and the regulation of endothelial nitric oxide synthase in the heart. Cardiovasc Res 69:788-797

7. Feron O, Dessy C, Opel DJ, Arstall MA, Kelly RA, Michel T (1998) Modulation of the endothelial nitric-oxide synthasecaveolin interaction in cardiac myocytes. Implications for the autonomic regulation of heart rate. J Biol Chem 273: 30249-30254

8. Fujimoto T (1993) Calcium pump of the plasma membrane is localized in caveolae. J Cell Biol 120:1147-1157

9. Fujimoto T, Nakade S, Miyawaki A, Mikoshiba K, Ogawa K (1992) Localization of inositol 1,4,5-trisphosphate receptor-like protein in plasmalemmal caveolae. J Cell Biol 119:1507-1513

10. Hausenloy DJ, Yellon DM (2006) Survival kinases in ischemic preconditioning and postconditioning. Cardiovasc Res 70: 240-253

11. Hausenloy DJ, Yellon DM (2007) Preconditioning and postconditioning: united at reperfusion. Pharmacol Ther 116:173-191

12. Hausenloy DJ, Tsang A, Yellon DM (2005) The reperfusion injury salvage kinase pathway: a common target for both ischemic preconditioning and postconditioning. Trends Cardiovasc Med 15:69-75

13. Horikawa YT, Patel HH, Tsutsumi YM, Jennings MM, Kidd MW, Hagiwara Y, Ishikawa Y, Insel PA, Roth DM (2008) Caveolin-3 expression and caveolae are required for isofluraneinduced cardiac protection from hypoxia and ischemia/reperfusion injury. J Mol Cell Cardiol 44:123-130

14. Jones KA, Jiang X, Yamamoto Y, Yeung RS (2004) Tuberin is a component of lipid rafts and mediates caveolin-1 localization: role of TSC2 in post-Golgi transport. Exp Cell Res 295:512-524

15. Juhaszova M, Zorov DB, Kim SH, Pepe S, Fu Q, Fishbein KW, Ziman BD, Wang S, Ytrehus K, Antos CL, Olson EN, Sollott SJ 
(2004) Glycogen synthase kinase-3beta mediates convergence of protection signaling to inhibit the mitochondrial permeability transition pore. J Clin Invest 113:1535-1549

16. Kamoun WS, Karaa A, Kresge N, Merkel SM, Korneszczuk K, Clemens MG (2006) LPS inhibits endothelin-1-induced endothelial NOS activation in hepatic sinusoidal cells through a negative feedback involving caveolin-1. Hepatology 43:182-190

17. Koneru S, Penumathsa SV, Thirunavukkarasu M, Samuel SM, Zhan L, Han Z, Maulik G, Das DK, Maulik N (2007) Redox regulation of ischemic preconditioning is mediated by the differential activation of caveolins and their association with eNOS and GLUT-4. Am J Physiol Heart Circ Physiol 292:H2060H2072

18. Krajewska WM, Maslowska I (2004) Caveolins: structure and function in signal transduction. Cell Mol Biol Lett 9:195-220

19. Kuzuya T, Hoshida S, Yamashita N, Fuji H, Oe H, Hori M, Kamada T, Tada M (1993) Delayed effects of sublethal ischemia on the acquisition of tolerance to ischemia. Circ Res 72: 1293-1299

20. Lisanti MP, Scherer PE, Tang Z, Sargiacomo M (1994) Caveolae, caveolin and caveolin-rich membrane domains: a signalling hypothesis. Trend Cell Biol 4:231-235

21. Marber MS, Latchman DS, Walker JM, Yellon DM (1993) Cardiac stress protein elevation 24 hours after brief ischemia or heat stress is associated with resistance to myocardial infarction. Circulation 88:1264-1272

22. Murry CE, Jennings RB, Reimer KA (1986) Preconditioning with ischemia: a delay of lethal cell injury in ischemic myocardium. Circulation 74:1124-1136

23. Palade G (1953) Fine structure of blood capillaries. J Appl Phys 24:1424

24. Parton RG, Way M, Zorzi N, Stang E (1997) Caveolin-3 associates with developing T-tubules during muscle differentiation. J Cell Biol 136:137-154

25. Patel HH, Head BP, Petersen HN, Niesman IR, Huang D, Gross GJ, Insel PA, Roth DM (2006) Protection of adult rat cardiac myocytes from ischemic cell death: role of caveolar microdomains and delta-opioid receptors. Am J Physiol Heart Circ Physiol 291:H344-H350

26. Patel HH, Tsutsumi YM, Head BP, Niesman IR, Jennings M, Horikawa Y, Huang D, Moreno AL, Patel PM, Insel PA, Roth DM (2007) Mechanisms of cardiac protection from ischemia/ reperfusion injury: a role for caveolae and caveolin-1. FASEB J 21:1565-1574

27. Peart JN, Headrick JP (2009) Clinical cardioprotection and the value of conditioning responses. Am J Physiol Heart Circ Physiol 296:H1705-H1720

28. Peng Y, Akmentin W, Connelly MA, Lund-Katz S, Phillips MC, Williams DL (2004) Scavenger receptor BI (SR-BI) clustered on microvillar extensions suggests that this plasma membrane domain is a way station for cholesterol trafficking between cells and high-density lipoprotein. Mol Biol Cell 15:384-396

29. Pike LJ (2003) Lipid rafts: bringing order to chaos. J Lipid Res 44:655-667

30. Raikar LS, Vallejo J, Lloyd PG, Hardin CD (2006) Overexpression of caveolin-1 results in increased plasma membrane targeting of glycolytic enzymes: the structural basis for a membrane associated metabolic compartment. J Cell Biochem 98:861-871

31. Scriven DR, Klimek A, Lee KL, Moore ED (2002) The molecular architecture of calcium microdomains in rat cardiomyocytes. Ann NY Acad Sci 976:488-499

32. Shaul PW, Anderson RG (1998) Role of plasmalemmal caveolae in signal transduction. Am J Physiol 275:L843-L851

33. Song KS, Scherer PE, Tang Z, Okamoto T, Li S, Chafel M, Chu C, Kohtz DS, Lisanti MP (1996) Expression of caveolin-3 in skeletal, cardiac, and smooth muscle cells. Caveolin-3 is a component of the sarcolemma and co-fractionates with dystrophin and dystrophin-associated glycoproteins. J Biol Chem 271:15160-15165

34. Steinberg SF, Brunton LL (2001) Compartmentation of G protein-coupled signaling pathways in cardiac myocytes. Annu Rev Pharmacol Toxicol 41:751-773

35. Tsutsumi YM, Horikawa YT, Jennings MM, Kidd MW, Niesman IR, Yokoyama U, Head BP, Hagiwara Y, Ishikawa Y, Miyanohara A, Patel PM, Insel PA, Patel HH, Roth DM (2008) Cardiacspecific overexpression of caveolin-3 induces endogenous cardiac protection by mimicking ischemic preconditioning. Circulation 118:1979-1988

36. Tsutsumi YM, Kawaraguchi Y, Horikawa YT, Niesman IR, Kidd MW, Chin-Lee B, Head BP, Patel PM, Roth DM, Patel HH (2010) Role of caveolin-3 and glucose transporter-4 in isofluraneinduced delayed cardiac protection. Anesthesiology 112:11361145

37. Williams TM, Lisanti MP (2004) The caveolin proteins. Genome Biol 5:214

38. Yamamoto M, Toya Y, Schwencke C, Lisanti MP, Myers MG Jr, Ishikawa Y (1998) Caveolin is an activator of insulin receptor signaling. J Biol Chem 273:26962-26968

39. Young LH, Ikeda Y, Lefer AM (2001) Caveolin-1 peptide exerts cardioprotective effects in myocardial ischemia-reperfusion via nitric oxide mechanism. Am J Physiol Heart Circ Physiol 280:H2489-H2495

40. Zhao ZQ, Corvera JS, Halkos ME, Kerendi F, Wang NP, Guyton RA, Vinten-Johansen J (2003) Inhibition of myocardial injury by ischemic postconditioning during reperfusion: comparison with ischemic preconditioning. Am J Physiol Heart Circ Physiol 285:H579-H588 